\title{
Contents, Vol. 56, Supplement 1, 1996
}

Pontes, J.E. (Detroit, Mich.) Issues on Early Diagnosis and Treatment of Localized Prostate Cancer

Tunn, U.W.; Acar, O.; Goldschmidt, A.J.W. Effects of Androgen Deprivation prior to Radical Prostatectomy in

(Offenbach a. Mam) 375 patients

Ferrari, P.; Castagnetti, G.; Ferrari, G.; $\quad$ Combination Treatment versus LHRH Alone in

Advanced Prostatic 13

Baisi, B.; Dotti, A. (Modena) Cancer

Fornara, P.; Jocham, D. (Lübeck) Clinical Study Results of the New Formulation Leuprorelin Acetate $\quad 1<$

Three-Month Depot for the Treatment of Advanced Prostate Carcinoma

Kienle, E.; Lübben, G.;

The German Leuprorelin Study Group

(Aachen)

Efficacy and Safety of Leuprorelin Acetate Depot for Prostate Cancer

23 